\title{
Gamma Oscillatory Firing Reveals Distinct Populations of Pyramidal Cells in the CA1 Region of the Hippocampus
}

\author{
Timothy J. Senior, John R. Huxter, Kevin Allen, Joseph O’Neill, and Jozsef Csicsvari \\ Medical Research Council Anatomical Neuropharmacology Unit, Department of Pharmacology, University of Oxford, Oxford OX1 3TH, United Kingdom
}

\begin{abstract}
Hippocampal place cells that fire together within the same cycle of theta oscillations represent the sequence of positions (movement trajectory) that a rat traverses on a linear track. Furthermore, it has been suggested that the encoding of these and other types of temporal memory sequences is organized by gamma oscillations nested within theta oscillations. Here, we examined whether gamma-related firing of place cells permits such discrete temporal coding. We found that gamma-modulated CA1 pyramidal cells separated into two classes on the basis of gamma firing phases during waking theta periods. These groups also differed in terms of their spike waveforms, firing rates, and burst firing tendency. During gamma oscillations one group's firing became restricted to theta phases associated with the highest gamma power. Consequently, on the linear track, cells in this group often failed to fire early in theta-phase precession (as the rat entered the place field) if gamma oscillations were present. The second group fired throughout the theta cycle during gamma oscillations, and maintained gamma-modulated firing at different stages of theta-phase precession. Our results suggest that the two different pyramidal cell classes may support different types of population codes within a theta cycle: one in which spike sequences representing movement trajectories occur across subsequent gamma cycles nested within each theta cycle, and another in which firing in synchronized gamma discharges without temporal sequences encode a representation of location. We propose that gamma oscillations during theta-phase precession organize the mnemonic recall of population patterns representing places and movement paths.
\end{abstract}

Key words: cell assembly; theta oscillation; theta-phase precession; place cells; synchronization; temporal coding

\section{Introduction}

Oscillations in the gamma frequency band $(30-80 \mathrm{~Hz})$ have been shown in a variety of brain structures (Eeckman and Freeman, 1990; Singer, 1993; Bragin et al., 1995; Chrobak and Buzsaki, 1998; Jacobs et al., 2007) and have been attributed to various cognitive processes including sensory binding (Singer, 1993; Engel et al., 2001), attention selection (Fries et al., 2001; Bauer et al., 2006), and memory (Lisman and Idiart, 1995; Fell et al., 2001; Howard et al., 2003). In most of these cases, they are thought to synchronize neuronal activity in different regions and thus serve as a common reference signal for temporal coding (Buzsaki and Chrobak, 1995; Engel et al., 2001; Buzsaki and Draguhn, 2004; Fries et al., 2007).

Gamma oscillations are prominent in the hippocampus (Buzsaki et al., 1983; Leung, 1992; Bragin et al., 1995; Penttonen et al., 1998; Csicsvari et al., 2003). In behaving animals two independent gamma generators have been identified: one in the CA3CA1 regions, which is intrahippocampal in origin, and another one in the dentate gyrus, which originates from the entorhinal

\footnotetext{
Received Oct. 15, 2007; revised Jan. 3, 2008; accepted Jan. 4, 2008.

This work was supported by the Medical Research Council, UK. The D. Phil. studentships of K.A. and T.S. were funded by the Wellcome Trust. We thank G. Buzsaki, M. Capogna, A. Czurko, T. Klausberger, P. Magill, 0. Paulsen, P. Somogyi, I. Vida, and M. Zugaro for their constructive comments on a previous version of this manuscript, and N. Campo-Urriza for technical assistance.

Correspondence should be addressed to Jozsef Csicsvari, Medical Research Council Anatomical Neuropharmacology Unit, Department of Pharmacology, University of Oxford, Mansfield Road, OX1 3TH Oxford, UK. E-mail: jozsef.csicsvari@pharm.ox.ac.uk.

DOI:10.1523/JNEUROSCI.4669-07.2008

Copyright $\odot 2008$ Society for Neuroscience $\quad$ 0270-6474/08/282274-13\$15.00/0
}

cortex (Bragin et al., 1995; Csicsvari et al., 2003). Hippocampal gamma oscillations can also be induced in vitro by the application of drugs activating muscarinic, kainate, or metabotropic glutamate receptors or by tetanic stimulation patterns (Whittington et al., 1995, 2001; Fisahn et al., 1998; Towers et al., 2002; Hajos et al., 2004; Palhalmi et al., 2004). In these slice studies, either interneuron-interneuron (I-I) or pyramidal cell-interneuron (P-I) interactions have been shown to generate the gamma rhythm, as predicted by modeling studies (Eeckman and Freeman, 1990; Whittington et al., 1995; Traub et al., 1996, 2000; White et al., 2000; Brunel and Wang, 2003; Borgers et al., 2005; Oren et al., 2006). In vitro gamma oscillations induced by the muscarinic agonist carbachol, which are generated by P-I interactions, share many features with in vivo gamma oscillations in the CA3-CA1 regions. They both have similar current source density profiles, and the gamma phase relationship between pyramidal cells and perisomatic innervating interneurons is comparable (Csicsvari et al., 2003; Mann et al., 2005; Oren et al., 2006). Because of these similarities, P-I interactions are thought to generate in vivo CA1-CA3 gamma oscillations as well. It has been suggested that local $\mathrm{P}-\mathrm{I}$ circuits in the CA1 and CA3 regions act as gamma generators and that the activity of these local gamma generators is transiently coupled (Csicsvari et al., 2003).

Gamma oscillations are nested within theta oscillations. Theta oscillations are strongly implicated in spatial and episodic memory sequences; for example, place cells that fire together within theta cycles represent the sequence of positions (movement trajectory) a rat traverses on a linear track (Skaggs et al., 1996; Dra- 
goi and Buzsaki, 2006). Theta phase precession, a gradual shift of theta spike timings as a function of location on the linear track (O'Keefe and Recce, 1993), enables place cells with overlapping place fields to form such sequences. Importantly, it has been proposed that cells firing in each gamma cycle represent one "item" in the sequence encoded in any given theta cycle (Lisman and Idiart, 1995). Phase precession itself is suggested to occur in gamma-steps and accordingly, place cells that are part of a temporal sequence may fire within discrete gamma steps during a theta cycle (Lisman, 2005). These sequences formed through successive gamma cycles have been suggested to encode short-term memory traces (Lisman and Idiart, 1995). In agreement with this, the results of previous studies have suggested a link between hippocampal gamma oscillations and short-term memory (Fuchs et al., 2007; Montgomery and Buzsaki, 2007; Sederberg et al., 2007).

However, the power of gamma oscillations is thetamodulated and is largest on the descending phases of theta oscillations (Bragin et al., 1995; Buhl et al., 2003). It is thus possible that place cells may not show gamma-modulated firing during the full theta cycle, preventing the formation of firing sequences in gamma intervals during phase precession. The gamma-locked firing of place cells has not yet been tested during theta-phase precession, so it is not known how theta modulation of gamma activity influences place-cell firing. The primary goal of this study was to test whether gamma oscillatory firing of place cells permits the gamma/theta-phase coding of place and the formation of spike sequences in discrete gamma steps. We examined whether pyramidal cells change their theta-related spike timing during gamma oscillations because of the theta modulation of gamma activity. We also specifically tested whether, on the linear track, the theta-phase precession profile of place cells was altered during gamma oscillations. We found that pyramidal cells split into two groups according to their gamma firing characteristics during waking gamma oscillations, but not in other states. One of the pyramidal cell groups did not change its theta-related spike timing during gamma oscillations whereas the other group showed such changes. This demonstrated that one group follows discrete theta-phase coding of place during gamma oscillations and is capable of maintaining full gamma-modulated temporal sequences encoding movement trajectories. We suggest that during gamma oscillations the other group is better suited to encode locations outside of a sequential context.

\section{Materials and Methods}

Surgery and recordings. The surgical and recording procedures, electrode preparation, implantation, and spike-sorting methods have been described previously (O’Neill et al., 2006). In short, eight adult male rats were implanted with 4-16 independently movable wire tetrodes under deep anesthesia using isoflurane (0.5-3\%), oxygen (1-2 l/min), and an initial dose of buprenorphine $(0.1 \mathrm{mg} / \mathrm{kg})$. Wire tetrodes constructed from 12- $\mu \mathrm{m}$-diameter tungsten wires (H-Formvar insulation with $\mathrm{Bu}$ tyral bond coat; California Fine Wire, Grover Beach CA) were attached to the microdrives, enabling their independent movement. During surgery, a craniotomy was performed above the dorsal hippocampus, centered at anteroposterior $-3.8 \mathrm{~mm}$ and mediolateral $2.5 \mathrm{~mm}$, relative to the bregma, and the dura mater removed and the electrode bundles were then implanted into the superficial layers of the neocortex. Two stainless steel microscrews (M1.4) driven into the bone above the cerebellum served as reference and ground electrodes.

After a 1 week recovery period, the tetrodes were lowered into the CA1 region of the hippocampus (close to the stratum pyramidale) over a further period of up to $7 \mathrm{~d}$. One or two 32-channel unity-gain preamplifier headstages (www.braintelemetry.com) were used to reduce cable movement artifacts. Wide-band $(0.1 / 1 \mathrm{~Hz}$ to $5 \mathrm{kHz})$ recordings were taken and amplified $\times 1000$ via a 64-channel Sensorium (Charlotte, VT) amplifier. Local field potentials and multiple-unit activity were continuously digitized at $20 \mathrm{kHz}$ using a 64-channel analog-to-digital converter computer card (United Electronics Industries, Canton, MA). Small infrared light-emitting diodes mounted on the headstage were used to track the location of the animal.

Food and water were available ad libitum for the animal before the recording procedures. The recording apparatus used consisted of rectangular boxes of different sizes ( $20-50 \mathrm{~cm}$ width). Black wooden walls (50 $\mathrm{cm}$ height) always closely surrounded the environment, and recordings were always performed in near darkness. Each recording session consisted of a sequence of sleep and waking spatial exploration sessions. Both waking and sleep sessions were at least $15 \mathrm{~min}$ long and appetitive rewards (e.g., chocolate sprinkles) were used to encourage locomotion during the exploration sessions.

All procedures involving experimental animals were performed with accordance of the Animals (Scientific Procedures) Act, 1986 (United Kingdom), and associated procedures under an approved project license.

Data analysis. Action potentials (spikes) were extracted from the digitally high-pass filtered $(0.8-5 \mathrm{kHz})$ signal. Spike features were then extracted using principal components analyses, and spikes from (putative) individual neurons were segregated using automatic clustering software (http://klustakwik.sourceforge.net/). Finally, the generated clusters were manually refined by a graphical cluster cutting program (Csicsvari et al., 1998). Only units with clear refractory periods ( $<2 \mathrm{~ms})$ in their autocorrelation were used for additional analysis. In addition, an isolation distance, based on Mahalabonis distance (Harris et al., 2001; SchmitzerTorbert et al., 2005), was calculated to ensure that spike clusters did not overlap during the course of the recordings. Pyramidal cells and interneurons were discriminated by their autocorrelations, firing rates and wave forms, as previously described (Csicsvari et al., 1999). Periods of waking spatial exploration, immobility and sleep were analyzed together. Stability of the cells was verified by plotting spike features over time and by plotting two-dimensional unit cluster plots in different sessions. We recorded the activity of $n=1267$ pyramidal cells and $n=199$ interneurons during periods of active and inactive waking and sleep. Subsequently, we recorded an additional $n=1232$ pyramidal cells in experiments where animals ran on a linear track (see below, Linear track recordings).

To identify periods of theta activity, the theta/delta power ratio was measured in $1600 \mathrm{~ms}$ segments (800 ms steps between measurement windows), using Thomson's multitaper method (Thomson, 1982; Mitra and Pesaran, 1999). Exploratory epochs included periods of locomotion and/or the presence of theta oscillations (as seen in the theta/delta ratio), with no $>2.4$ s (i.e., two consecutive windows) of transient immobility. Waking immobility sessions were selected when both the speed and theta/delta ratio dropped below a preset threshold (speed, $<5 \mathrm{~cm} / \mathrm{s}$; theta/ delta ratio, $<2$ ) for at least $2.4 \mathrm{~s}$. Sleep sessions were recorded separately and were identified by occasional occurrence of rapid eye movement (REM)-theta periods and the presence of slow-wave oscillations.

For the detection of theta-oscillatory waves, the local field potential was filtered $(5-28 \mathrm{~Hz})$ and the negative peaks of individual theta waves were detected. For gamma oscillations, local field potentials were bandpass filtered $(30-80 \mathrm{~Hz})$ and the power (root mean square) of the filtered signal was calculated for each electrode (Csicsvari et al., 2003). Gamma oscillatory periods were detected and used for subsequent analysis. Gamma epochs began when gamma power exceeded 2 SD above the mean for the recording session, and ended when gamma power dropped below $1 \mathrm{SD}$, and had to include detection of individual gamma cycle peaks and troughs ( $>2$ SD) (supplemental Fig. 1, available at www.jneurosci.org as supplemental material). These gamma epochs represented on average $12.3 \%$ of the total recording period and $13.9 \%$ of waking theta oscillatory periods.

The phase relationship between unit activity and gamma oscillations was calculated as follows. Each spike was assigned to a given phase (bin size of $20^{\circ}$ ) of the normalized gamma cycle, and a phase histogram was calculated by summing unit discharges that occurred at different phases. Phase histograms were normalized by dividing each bin by the number of gamma cycles, and the probability of unit discharge at each phase was computed. Rayleigh tests (Fisher, 1993) of the unit-discharge gamma 
phases were used to determine whether individual units showed significant phase locking to gamma waves. The average angle of different unit discharge gamma phases representing their preferred phases were calculated as the circular mean of angles. To calculate the circular mean, each phase is expressed as a vector, and the average vector of these phase vectors is calculated. The circular mean phase represents the angle of this average vector whereas the length of this average vector was used to measure the strength of gamma phase locking (Fisher, 1993). Circular mean phases were reported together with their $95 \%$ confidence interval (Fisher, 1993). The Watson-Williams circular test was used to quantify differences of phase locking between neuron populations (Kanji, 1999).

To determine whether a frequency histogram with two peaks was sampled from a bimodal and not a unimodal distribution, a kernel functionbased bootstrapping procedure was used (Silverman, 1981; Efron and Tibshirani, 1993; Paulsen and Heggelund, 1996). In this procedure, smoothed density estimates of the cell-count histogram were generated using a Gaussian kernel function. We determined the minimal smoothing window size $h_{1}$ (the SD of the Gaussian kernel function) which resulted in a unimodal distribution (or bimodal if bimodality was being tested). Bootstrap samples, each with the same number of data points as in the original cell-count histogram, were drawn from a smoothed density estimate with window size $h_{1}$. According to the bootstrap hypothesis, $h_{1}$ is the smallest window size that results in a unimodal (or bimodal) smoothed estimate. Therefore all bootstrap samples should require a larger minimum smoothing window size $\left(h_{1}^{*}\right)$ for a unimodal distribution than was required for the original samples (i.e., $h_{1}{ }^{\star}>h_{1}$ ). The probability of the hypothesis is estimated by the number bootstrap samples in which $h_{1}^{*}>h_{1}$, divided by number of bootstrap samples. Altogether, 500 bootstrap samples were drawn; therefore, if $h_{1}{ }^{*}>h_{1}$ was not true for any of our 500 bootstrap samples, we rejected the hypothesis $(p<0.002)$.

Place rate-maps were calculated as described previously (Harris et al., 2001) by a kernel-based method in which both the firing rate and occupancy maps were smoothed with a Gaussian kernel function $(\mathrm{SD}, 3 \mathrm{~cm})$. To differentiate locations inside and outside the place fields, a firing rate threshold was set. The firing rate threshold was set automatically by measuring the mean, baseline firing rate in $50 \%$ of the place rate-map bins with the lowest firing rate. The threshold for inside the place field was set to two times the baseline rate and bins with less than baseline rate were considered as outside the place field.

Linear track recordings. An additional six adult rats were implanted with 16 independently movable tetrodes. After recovery, food was restricted to maintain weight at $\sim 85 \%$ (age matched) of the starting weight, and the rats were trained to run back and forth between the two ends of a linear or circular track (162 and $204 \mathrm{~cm}$ long, respectively). The spikes of 1232 pyramidal cells were recorded from the upper blade of the CA region of the hippocampus. In some of our tetrodes $200 \mathrm{~Hz}$ ripples were not observed during the task. These tetrodes may have been located in the CA3a area instead of the target CA1 area. These putative CA3 cells, however, showed similar gamma-related firing to that of the CA1 region and therefore were included in the phase precession analysis.

The linear place field of each cell was defined as a continuous area extending from the peak rate location until the firing rate dropped below $20 \%$ of the peak rate. The runs in opposite directions were treated separately and only data associated with $>5 \mathrm{~cm} / \mathrm{s}$ movement speed were selected. The criteria used to select cells for subsequent analysis were as follows. First, only the cells with a place field covering $<40 \%$ of the linear track and in which at least $60 \%$ of the spikes occurred within the place field were selected. Place fields also needed to contain at least 200 action potentials ( $>20$ during gamma oscillations) and those with a center located at $<15 \mathrm{~cm}$ from the end of the maze were rejected. Second, circular-linear regression was used to test if a cell showed significant theta-phase precession $(p<0.05)$ and only cells with significant thetaphase precession and significant gamma phase locking were analyzed.

Place-phase maps were calculated in a similar manner to those of place-rate maps. The spike-count maps (as a function of the rat's location on the linear track and theta phase) and their associated occupancy maps were calculated (equal occupancy probability being assumed for differ- ent theta phases). These were smoothed with a Gaussian kernel function $\left(\mathrm{SD}, 15 \mathrm{~cm}\right.$ and $72^{\circ}$ ) as described above and divided by each other.

\section{Results}

\section{Preferred gamma phases of pyramidal cells and interneurons}

Local field potential and multiple-unit activities were recorded in the CA1 pyramidal layer during both waking and sleep periods. Gamma oscillatory waves were detected in the CA1 region in time periods when the gamma power of the local field potentials was above a preset threshold (see Materials and Methods) (Csicsvari et al., 2003). We compared the gamma oscillation-associated network responses in different behavioral states (waking theta, immobility states, slow-wave and rapid eye movement sleep). We selected only those cells that exhibited significant phase locking ( $p<0.01$, Rayleigh test) to gamma oscillations. The percentage of cells that phase locked to gamma oscillations varied in different behavioral states; it was highest during waking theta states (pyramidal cells, 32\%; interneurons, $85 \%$ ) and lowest during REM sleep (pyramidal cells, 4\%; interneurons, 45\%) (supplemental Fig. 2, available at www.jneurosci.org as supplemental material). Note that REM periods were much shorter than other periods, so in many cases cells did not fire sufficient numbers of action potentials to reach a significance level. In all states, a larger proportion of interneurons exhibited significant gamma phase locking than pyramidal cells. Moreover, the percentage of significantly gamma phase-locked interneurons remained larger, even when interneuron spikes were downsampled so spike numbers resembled those for pyramidal cells (supplemental Fig. 2, available at www.jneurosci.org as supplemental material).

To compare the gamma spike timing of pyramidal cells and interneuron populations, their average firing probabilities were calculated at different phases of gamma oscillations (i.e., average gamma firing-phase histograms) (Fig. $1 A, B$ ). In all four states, the pyramidal cell population fired earlier than the interneuron population. The mean gamma firing phases of pyramidal cell and interneuron populations were significantly different in all four states (all $p<0.0001$, Watson-Williams test). The phase differences were the smallest during waking theta states and largest during REM sleep (waking theta, $64.5^{\circ}$; waking immobility, $86.6^{\circ}$; slow-wave sleep, $74.5^{\circ}$; REM sleep, $99.0^{\circ}$ ). Interneuron firingphase histograms were similar in all four states (Fig. $1 B$ ). In contrast, pyramidal cell histograms were different during the waking-theta state, exhibiting a shifted gamma phase preference and reduced gamma modulation compared with other states (Fig. $1 A$ ).

For a comparison of the gamma-related firing of different cells, the average gamma firing phase (preferred gamma phase) of different cells was summarized in a frequency histogram (cellcount histogram). As with the average firing-phase histograms, pyramidal cell-count histograms were different during the waking-theta state compared with other states $\left(p<0.0001, \chi^{2}\right.$ test) (Fig. 1C,E). During waking-theta periods, two peaks were detected in the pyramidal cell-count histograms (Figs. $1 C$, supplemental Fig. 3, available at www.jneurosci.org as supplemental material), whereas in other states a single peak was observed (Fig. $1 E)$. During waking-theta states, pyramidal cells fired either near the trough or ascending gamma phases, whereas in other states they fired at the trough of gamma waves (Fig. 1C,E, G). The cellcount histograms of interneurons were similar $\left(p>0.25, \chi^{2}\right.$ test $)$ (Fig. $1 D, F$ ) in all four states. Two peaks were present in all four states, with the majority of interneurons firing at rising, and a minority forming a second peak at descending, phases.

A bootstrapping procedure (Silverman, 1981; Efron and Tib- 

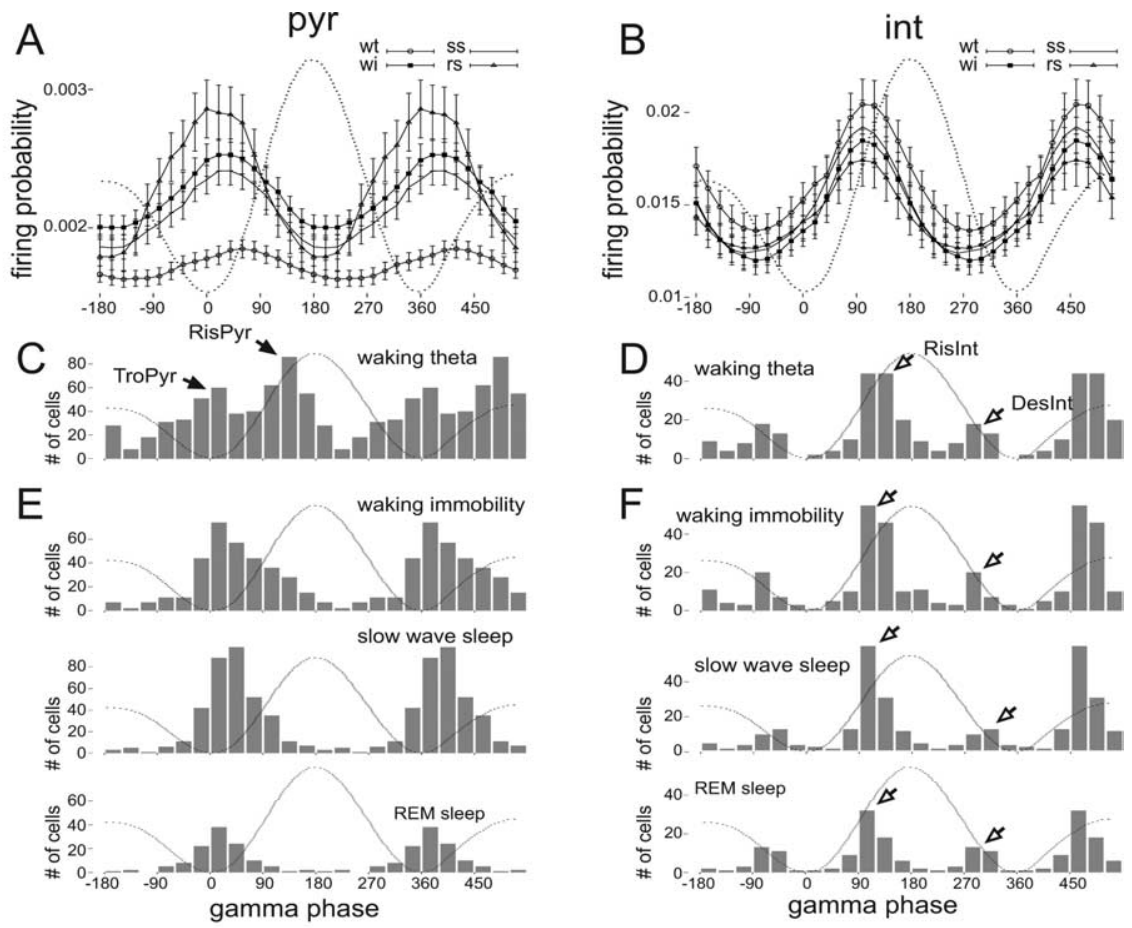

G

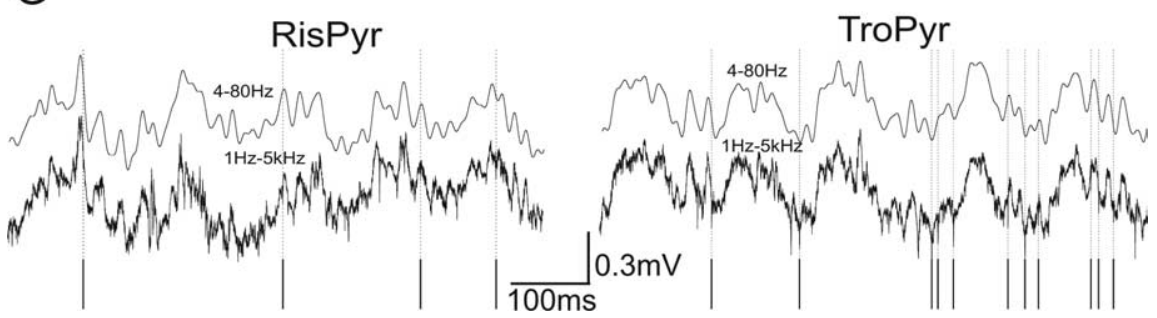

Figure 1. Gamma network response of CA1 pyramidal cells and interneurons during different behavioral states. $A, B$, Mean ( \pm SE) gamma firing-phase histograms of pyramidal cell (pyr) and interneuron (int) populations. The firing probability of individual cells was calculated at different phases of gamma oscillations and averaged. wt, Waking-theta; wi, waking immobility; ss, slow-wave sleep; rs, REM sleep. $\mathbf{C} \boldsymbol{F}$, The mean of action potential gamma phases (i.e., preferred gamma phase) was calculated and summarized in frequency (cell-count) histograms during waking-theta periods $(\boldsymbol{C}, \boldsymbol{D})$ and in waking immobility, slow-wave sleep, and REM sleep epochs $(\boldsymbol{E}, \boldsymbol{F})$. Of the 1267 pyramidal cells and 199 interneurons recorded, we included in the analysis only cells with significant gamma modulation (Rayleigh test, $p<0.01$; wt: int, $n=171$; pyr, $n=415$; wi: int, $n=160 ;$ pyr, $n=182$; ss: int, $n=140 ;$ pyr, $n=215$; rs: int, $n=87$; pyr, $n=55$ ). Dotted trace, Representative averaged field potential of a gamma oscillatory wave. Note the dual-peak separation of pyramidal cells during waking-theta periods (filled arrowheads pointing to TroPyr and RisPyr pyramidal groups) and similar separation of interneurons in all states (open arrows pointing to RisInt and DesInt groups). G, Spike timing of a RisPyr and a TroPyr cell is shown relative to the simultaneously recorded local field potential recorded from the same electrode. Top traces show bandpass-filtered $(4-80 \mathrm{~Hz})$ potentials, whereas bottom traces represent wide-band ( $1 \mathrm{~Hz}$ to $5 \mathrm{kHz}$ ) traces. Note that RisPyr cell (left) had a preference to fire near the peak of gamma waves, whereas the TroPyr cell fired mainly near the trough.

shirani, 1993; Paulsen and Heggelund, 1996) was used to test whether the two peaks observed in the cell-count histograms could have been detected by chance, sampling from a unimodal distribution (see Materials and Methods). This analysis rejected the hypothesis that pyramidal histograms (during waking-theta oscillations) or interneurons (all states) were drawn from a unimodal distribution (all $p<0.002$ ). Thus, both pyramidal cells (during waking theta) and interneurons (during all states) do not simply show random variation of their preferred gamma phases, but are instead distributed around two separate mean phases, in two gamma-phase clusters.

To establish whether pyramidal cells that fire at different gamma phases (i.e., in different phase clusters) show additional differences in their network firing properties, they were subdi- vided according to their preferred gamma phases during waking-theta oscillations in the subsequent analyses. They were split into a trough-firing pyramidal (TroPyr) group in interval $\left[-150^{\circ}, 60^{\circ}\right]$ (i.e., $-150^{\circ}$ $\left.<x \leq 60^{\circ}\right)$, and a rising-phase pyramidal (RisPyr) group in interval $\left[60^{\circ}, 210^{\circ}\right]$. Similar divisions were made for interneurons to differentiate the secondary group of interneurons that fired at descending gamma phases, resulting in a rising-phase interneuronal (RisInt) group in interval $\left[0^{\circ}, 180^{\circ}\right]$ and descending-phase interneuronal (DesInt) group in interval $\left[-180^{\circ}, 0^{\circ}\right]$.

\section{Differences in firing rate, burst firing tendency, and spike waveforms between TroPyr and RisPyr cells}

The average firing rate of TroPyr cells was significantly higher than that of RisPyr cells ( $p<0.001, t$ test), although the groups overlapped and many cells in both groups fired at lower $(<2 \mathrm{~Hz})$ firing rates (Fig. $2 B$ ). The average interspike interval (ISI), using $100 \mathrm{~ms}$ averaging windows, was significantly shorter for TroPyr cells than for RisPyr cells ( $p<0.0001, t$ test). The cell-count histogram of average ISI intervals separated better than firing rates (Fig. 2C). Differences of burst firing tendency may have caused the differences in the average ISI between cells groups. Indeed, the average autocorrelation function showed TroPyr cells were almost twice as likely to fire a second action potential within $10 \mathrm{~ms}$ (i.e., fire in burst) than RisPyr cells (Fig. 2D).

Next, we compared the average wideband ( $1 \mathrm{~Hz}$ to $5 \mathrm{kHz}$ ) filtered extracellular spike waveforms of the two pyramidal cell groups. We calculated separately the average waveform of each cell, which was used to measure their wave form characteristics. Compared with TroPyr cells, RisPyr cells had narrower spike waveforms and their action potentials were followed by larger amplitude afterpotentials, as indicated in Figure $2 A$, showing the grand mean of the average waveforms for the two groups. Furthermore, cell-by-cell comparisons of the spike duration (measured at $25 \%$ of the maximum amplitude) showed RisPyr cells had a significantly narrower waveform $(0.428 \pm 0.007 \mathrm{~ms}, n=196)$ than TroPyr cells $(0.496 \pm 0.009 \mathrm{~ms}, n=190, p<0001, t$ test $)$. Similarly, RisPyr cells showed significantly larger relative amplitude spike afterpotentials on their averaged waveforms than TroPyr cells $(p<0.001, t$ test). Differences in spike durations between the two cell classes were not because of their different tendencies to fire bursts: differences remained significant whether single spikes or the first, second, and third action potentials of the bursts were considered (Fig. 2E) (all $p$ values $<0.0001, t$ test). We performed similar analysis for interneuron classes as well; the two groups did 
not show significant differences in their average firing rate, ISI intervals, or spike durations (all $p$ values $>0.8$ ).

Preferred gamma phases in waking-theta and sleep states and during exploration of familiar and novel environments

We examined whether the gamma phase of cell firing changes between waking-theta and sleep states. Pyramidal cells of the TroPyr and RisPyr groups were only distinguishable during waking-theta periods whereas all pyramidal cells fired near the trough of gamma oscillations during sleep (Fig. 1C,E). We therefore tested whether RisPyr cells stopped being gamma modulated during sleep, or merely shifted their gamma firing phases toward the trough where pyramidal cells tend to fire during sleep. The preferred gamma phases of the same cells during sleep and waking-theta periods are shown in a scatter plot (Fig. $3 A, B)$. This plot shows that both TroPyr and RisPyr cells significantly changed their preferred gamma phases (in opposite directions) from waking-theta to sleep periods (all $p$ values $<0.0001$, Rayleigh test) (Fig. $3 A$ ); RisPyr cells shifted their firing toward the trough. In addition, a larger proportion of the TroPyr cells maintained a significant gamma phase locking during sleep than the RisPyr cells (TroPyr, 49.5\%; RisPyr, $23.3 \%)$. The preferred gamma phases of pyramidal cells during sleep and waking theta correlated significantly $(r=0.58 ; p<$ 0.0001, circular-circular regression). Gamma phases of individual interneurons remained similar between sleep and waking-theta states similar to their network responses (Fig. 3B). Preferred gamma phases of interneurons were strongly correlated across both states $(r=0.75, p<$ 0.0001 , circular-circular regression).

To see whether cells maintain their gamma phase preference during exploration of different environments, we compared gamma phases between novel and familiar environments. For interneurons and pyramidal cells with significant gamma phase locking, the mean gamma phase of individual cells was strongly correlated across environments (Fig. 3C,D) (pyramidal cells, $r=0.69$; interneuron, $r=0.83$, all $p$ values $<0.001$, circular-circular regression). However, many pyramidal cells were significantly gamma-phase locked in one environment but not the other: $61 \%$ exhibiting significant gamma phase locking in familiar environments failed to do so in novel environments, whereas $53 \%$ with significant gamma phase locking in novel environments were not phase locked in familiar environments.

These results suggest that interneurons maintain similar gamma firing phases across sleep and waking states as well as during exploration of familiar and novel environments. In contrast, many of the RisPyr pyramidal cells ceased to show gammalocked firing during sleep, whereas the remainder changed their
E

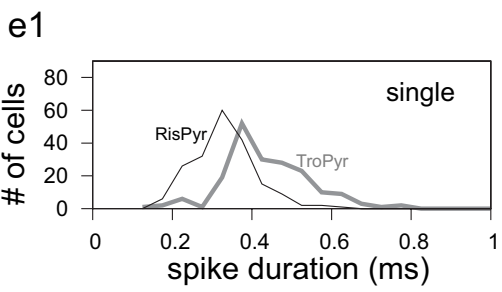

e2

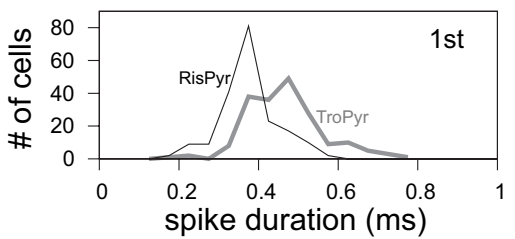

e3

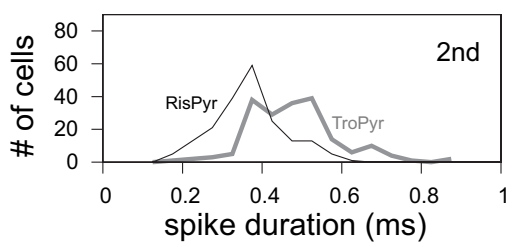

e4

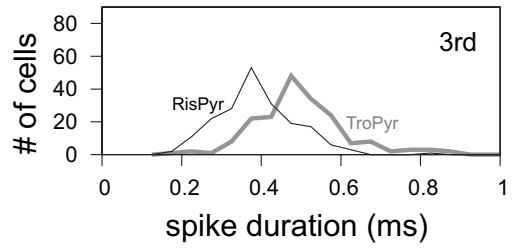

Figure 2. Differences in firing rate, burst firing tendency, and action-potential waveforms between TroPyr and RisPyr cells. $A$, Average extracellular action-potential waveforms for TroPyr and RisPyr cells, using wide-band filtered ( $1 \mathrm{~Hz}$ to $5 \mathrm{kHz}$ ) action potentials. First, the average waveforms of individual cells were calculated. These were subsequently normalized relative to the e-to-peak amplitude. Waveforms of different cells were further averaged to calculate the average group waveform of 列 was similar. Bin at zero is not plotted and bin-size of $1 \mathrm{~ms}$ was used. $\boldsymbol{E}$ (ell-count histograms of spike duration at $25 \%$ of the maximum amplitude (see illustration in $\boldsymbol{A}$ ) were calculated separately for single spikes and the first, second, and third spikes of a burst. TroPyr cells had wider waveforms in all four cases (all $p$ values $<0.0001$ ); hence, the waveform differences between the two cell classes were not because of their different tendencies to fire bursts.

gamma firing phases during sleep and fired closer to the trough of gamma oscillations. Nevertheless, pyramidal cells did not change their gamma phase in different exploration sessions of familiar and novel environments although many cells did not show gamma locking in both environments.

\section{Theta phase locking of gamma-modulated cells}

The power of gamma oscillations is periodically modulated by theta oscillations (Fig. $4 B$, average traces) and, in the CA1 region, the power is highest at the descending phase of theta oscillations (Bragin et al., 1995; Buhl et al., 2003). In agreement with this, we found that the probability of gamma wave occurrence was significantly modulated by theta oscillations (supplemental Fig. 4A, available at www.jneurosci.org as supplemental material), and reached a maximum at descending theta phases (circular mean, 
A
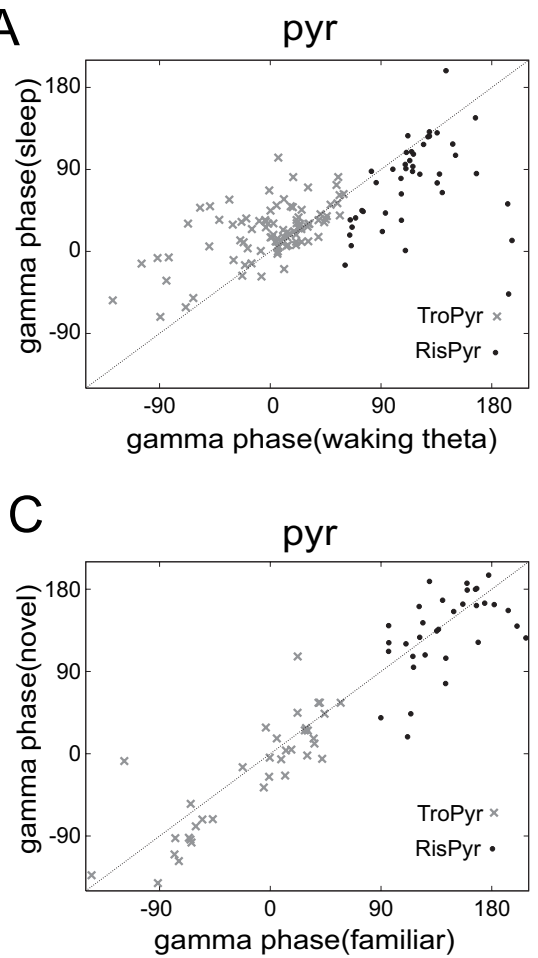

$\mathrm{B}$

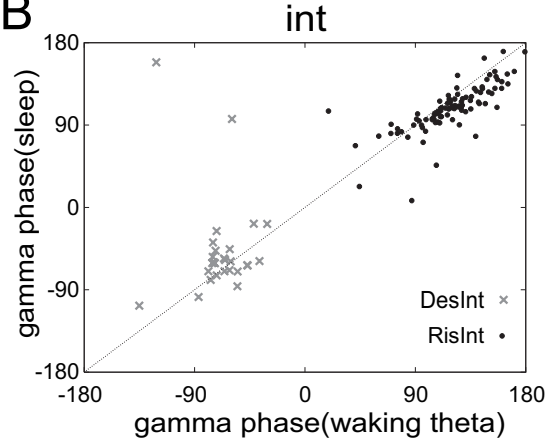

D

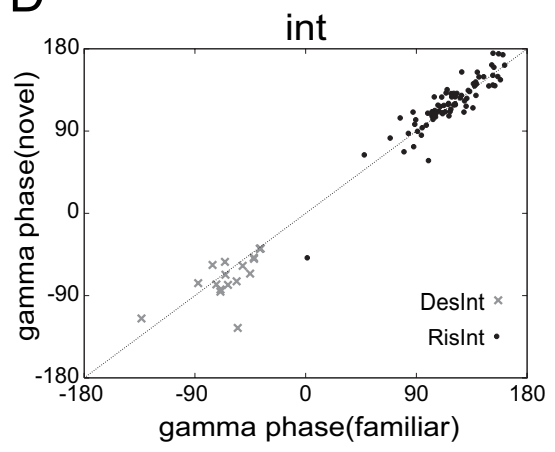

Figure 3. Gamma firing phases are correlated during waking-theta and sleep states and during exploration of familiar and novel environments. $\boldsymbol{A}, \boldsymbol{B}$, The preferred gamma phases of cells during waking-theta periods were plotted against their preferred gamma phases during sleep. Only cells with significant phase locking (Rayleigh test, $p<0.01$ ) in both states were included. Pyramidal cells from the $\operatorname{TroPyr}(n=91)$ and $\operatorname{RisPyr}(n=43)$ groups $(A)$ and interneurons from the RisInt $(n=105)$ and Desint $(n=29)$ groups $(\boldsymbol{B})$ are plotted separately. Pyramidal cells were plotted in the $\left[-150^{\circ}, 210^{\circ}\right]$ interval so that the Desint and RisInt groups are displayed continuously. Diagonal line, $x=y$ (waking phase $=$ sleeping phase). $\boldsymbol{C}, \boldsymbol{D}$, The preferred gamma phases of pyramidal cells $(\boldsymbol{C})$ and interneurons $(\boldsymbol{D})$ measured during exploration of familiar environments were plotted against those of novel environment exploration. Preferred gamma phases were measured during waking-theta periods. Only cells with significant phase locking (Rayleigh test, $p<0.01$ ) in both familiar and novel environments were included (RisPyr, $n=33$; TroPyr, $n=36$; DesInt, $n=17$; RisInt, $n=90$ ). Note on the plots that gamma phases were more similar across the two conditions for interneurons than for pyramidal cells.

$-97.1 \pm 7.8^{\circ}, n=197, p<0.0001$, Rayleigh test). Nevertheless, gamma waves were detected in all phases of the theta oscillations. The phase locking strengths of pyramidal cells and interneurons were in a similar range for both gamma and theta oscillations during active waking periods, indicating that cells are mutually influenced by both of these network oscillations (supplemental Fig. 5, available at www.jneurosci.org as supplemental material).

During gamma oscillations, cells may preferentially fire at theta phases where gamma field power is high. Because gamma is not constantly present in the CA1 region, it is possible that cells may fire at different theta phases depending on whether the gamma oscillation is present at a given theta cycle. We therefore examined whether cells change their theta phases when they fire during gamma oscillations.

First, we calculated the preferred theta phases of cells independent of gamma oscillations. The preferred theta and gamma phases of individual pyramidal cells were plotted together in a scatter plot (Fig. 4A). Additionally, the cell-count histogram of preferred theta phases was calculated separately for the different groups for the whole session (supplemental Fig. $4 B$, available at www.jneurosci.org as supplemental material). Both pyramidal cell groups fired near the trough of theta oscillations as shown. However, their mean theta phases were significantly different (RisPyr, $-27.9 \pm 11.2^{\circ} ; n=168$; TroPyr, $20.6 \pm 13.4^{\circ}, n=178$; $p<0.0001$, Watson-Williams test).
Next, we calculated the preferred theta phase of pyramidal cells during gamma oscillations to see whether cells changed their theta-phase preference during gamma oscillations. The theta/gamma phase scatter plots (Fig. $4 \mathrm{~B}$ ) and the cell-count histograms of preferred theta phases (supplemental Fig. 4C, available at www.jneurosci.org as supplemental material) were calculated only during gamma oscillations. Most of the RisPyr cells fired at descending theta phases (where gamma field power is higher), whereas TroPyr cells did not show such phase preference (Fig. $4 B$, supplemental Figs. $4 C, 6 A$, available at www.jneurosci.org as supplemental material). To quantify this effect, we measured the thetaphase distance of cell firing relative to theta phase of maximal gamma power (estimated by the preferred theta phase of gamma waves). This phase distance was significantly less for RisPyr than for TroPyr cell groups (RisPyr, $21.8 \pm 7.7^{\circ}, n=132$; TroPyr, $72.1 \pm 11.2^{\circ}, n=138 ; p<0.0001$, Watson-Williams test). Additionally, RisPyr cells showed significantly larger theta-phase changes (phase distances between average and gamma-period theta phases, $\left.47.4 \pm 8.4^{\circ}, n=132\right)$ than did TroPyr cells $\left(24.7 \pm 7.6^{\circ}, n=138 ; p<0.0001\right.$, Watson-Williams test) (supplemental Fig. $7 A$, available at www.jneurosci.org as supplemental material). Interneurons of the RisInt class also changed their theta phases during gamma oscillations, firing when gamma field power was high (supplemental Figs. $7 B, 8$, available at www.jneurosci.org as supplemental material).

In summary, during gamma oscillations, RisPyr changed their firing toward theta phases associated with maximal gamma power, whereas TroPyr firing was less tightly locked to the theta phase where gamma is maximal and closer to their average theta phases, showing only minor theta-phase changes.

\section{Gamma phase locking during complex spike bursts}

Pyramidal cells may not phase lock to gamma oscillations during burst firing; the stronger input and intrinsic conductances activated during bursts may be able to overcome gamma-modulated perisomatic inhibition. Alternatively, the first spike of the burst may phase lock to gamma, in which case successive spikes would follow the burst interval, thus altering the gamma phase of these spikes. To test the gamma phase locking of burst firing, we examined the preferred phase of gamma oscillations for single spikes and first, second and third spikes of the burst during wakingtheta periods. Successive action potentials with $<10 \mathrm{~ms}$ interspike interval were considered as part of a burst. Pyramidal cells fired close to their average preferred gamma phases when they fired single spikes (Fig. 5A,B, supplemental Fig. 9, available at www.jneurosci.org as supplemental material). Pyramidal cells of the TroPyr group fired earlier for the first spike of the burst and at later gamma phases for the second and third action potentials (Fig. 5B, supplemental Fig. 9B, available at www.jneurosci.org as supplemental material). However, the majority of the cells in the 
A

all session

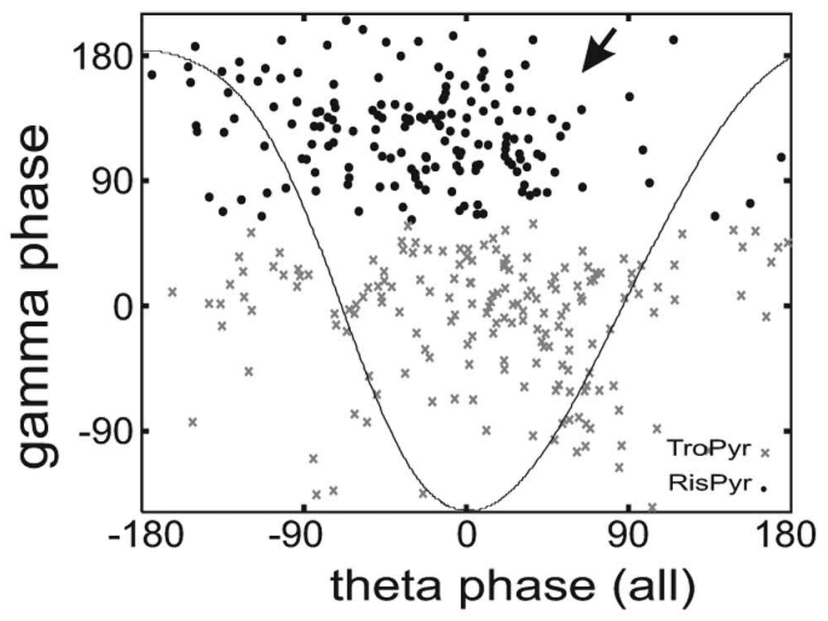

B

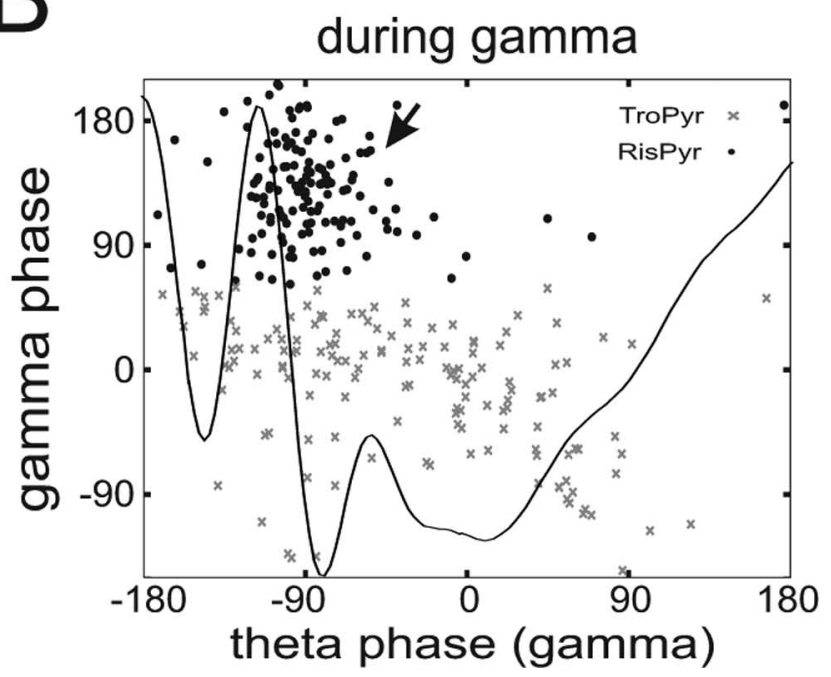

Figure 4. Changes of theta-phase preference of pyramidal cells during gamma oscillations. $A$, The scatter plots of the preferred theta and gamma phases measured for pyramidal cells during waking exploration sessions for the whole session [theta phase (all)]. Only pyramidal cells that showed both significant theta and gamma phase locking (Rayleigh test, $p<0.01$ ) are included. The preferred gamma phase of pyramidal cells was plotted in the $\left[-150^{\circ}, 210^{\circ}\right]$ interval on the scatter plot so that the TroPyr and RisPyr groups are continuously displayed (RisPyr, $n=168$; TroPyr, $n=178$ ). Traces on the plots show representative averaged waveforms of a field oscillatory theta wave. $\boldsymbol{B}$, The scatter plots of the preferred theta and gamma phases measured during gamma oscillatory periods [theta phase (gamma)] (RisPyr, $n=141$; TroPyr, $n=145$ ). Traces on the plots show representative averaged theta-gamma field oscillatory waveform averaged in reference to the largest amplitude gamma oscillatory wave times during each theta cycle. Arrows on the plots highlight that RisPyr cells changed their theta phases during gamma oscillations and fired at descending theta phases compared with their phases measured during the whole session.

RisPyr group stopped showing significant phase locking to gamma oscillation when they fired bursts of action potentials (Fig. 5A).

Next, we tested how well the gamma phase locking during burst firing predicted whether a cell was in the RisPyr or TroPyr group. Most of the cells that showed significant gamma locking during a burst belonged to the TroPyr group (Fig. 5C,D); 79.1\% of cells were part of the TroPyr group when the first action potential of the burst was considered and this value further improved to 83.6 and $85.3 \%$ for the second and third action potentials, respectively (Fig. 5D). Note, however, that a small number of the RisPyr pyramidal cells continued to show significant gamma modulation during bursts firing (Fig. $5 A, C$ ).

As shown in Figure 2, RisPyr cells exhibited a reduced tendency to fire in burst. So it is possible that some of them did not show significant gamma phase locking during the burst because fewer spikes were available to establish the significance level of phase locking. To address this issue, we measured the strength of their gamma modulation during bursts (i.e., the length of their mean phase vector) (see Materials and Methods) because this measure does not improve with spike numbers. In this analysis we only included cells that showed overall significant gamma modulation but may not have shown significant gamma modulation during single spike or burst firings. For single spikes, RisPyr cells showed a significantly longer vector length than TroPyr cells (RisPyr, $0.16 \pm 0.005, n=207$; TroPyr, $0.13 \pm 0.004$, $n=207 ; p<0.001)$. However this relationship was reversed during bursts, RisPyr cells showing significantly shorter vector lengths than TroPyr cells (first spike, RisPyr, $0.099 \pm 0.005 n=$ 152; TroPyr, $0.146 \pm 0.006, n=184, p<0.001$; second and later spikes, RisPyr, $0.111 \pm 0.005 n=217$; TroPyr, $0.146 \pm 0.005, n=$ $298, p<0.001)$. This analysis confirmed that RisPyr cells show reduced gamma phase locking during bursts independent of their spike numbers during the burst.

\section{Place-cell firing during gamma oscillation}

We tested whether place-selective firing is maintained during gamma oscillations and, if so, whether the preferred gamma phase of place cells is altered when they fire inside their place field compared with outside. Action potentials of the cells during waking-theta periods were separated depending on whether they fired inside or outside the place field (see Materials and Methods), and separate gamma firing-phase histograms were calculated for each condition. On average, the firing probability of cells inside the place field was approximately three times higher for the RisPyr cells and 2.5 times higher for the TroPyr cells, showing that place-related firing is maintained during gamma periods (Fig. 6A, B). In addition, gamma modulation of cells was maintained both inside and outside the place field. The preferred gamma phases of cells were similar inside versus outside for either RisPyr cells ( $p>0.5$, Watson Williams test) or TroPyr cells ( $p>$ 0.1 , Watson Williams test) (supplemental Fig. $10 A, B$, available at www.jneurosci.org as supplemental material). Therefore, gamma phase of pyramidal cells was not altered when they fired at a lower rate outside their place field. Nevertheless, absolute gamma modulation of place cells (i.e., trough-to-peak firing probability increase on the average firing-phase histogram) improved inside the place field compared with outside (Fig. 6A,B); the firing rate increase inside the place field (relative to outside) was also gamma modulated.

\section{Gamma oscillatory firing on the linear track}

Because we found that place-selective firing was maintained during gamma oscillations, it is possible that gamma-modulated temporal sequences are formed during theta-phase precession (Lisman, 2005; Koene and Hasselmo, 2007). To test directly whether this is the case, we recorded place cell activity during theta-phase precession and we examined whether the phase precession profile of cells was altered during gamma oscillations. Because RisPyr cells changed their preferred theta phase and fired 


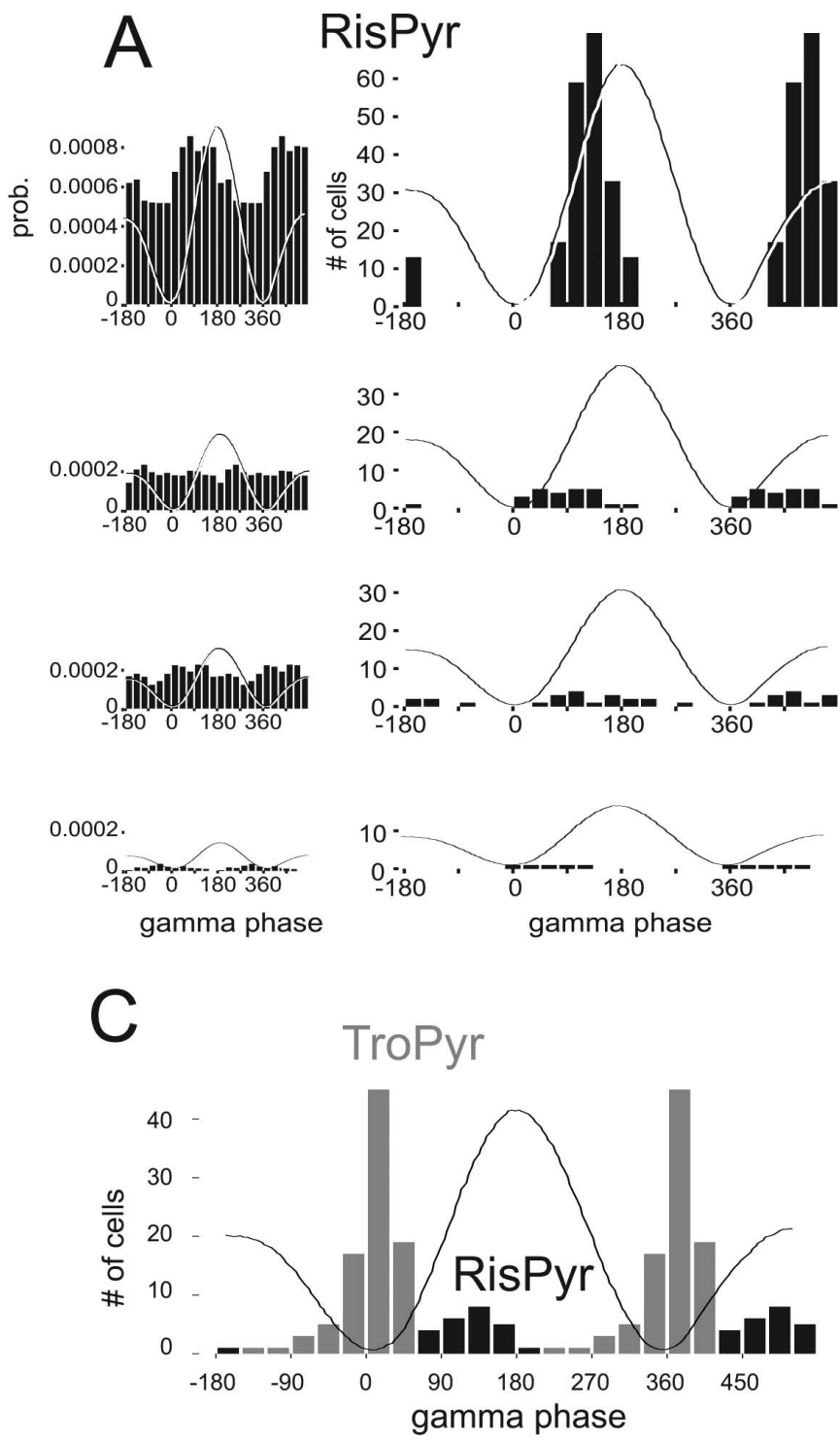

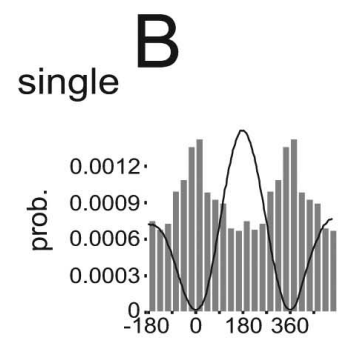

\section{TroPyr}

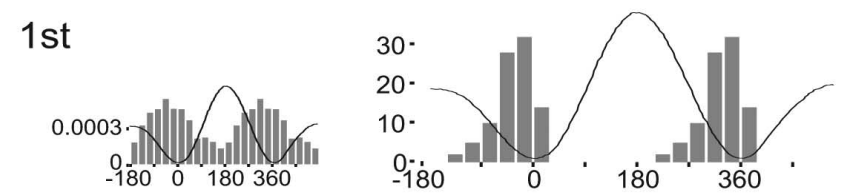

2nd
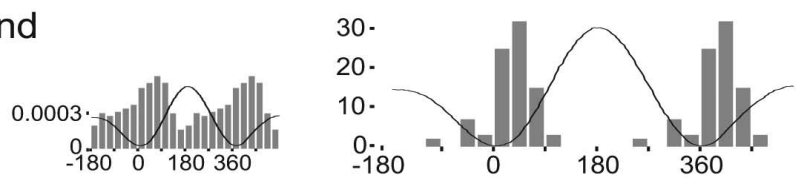

3 rd
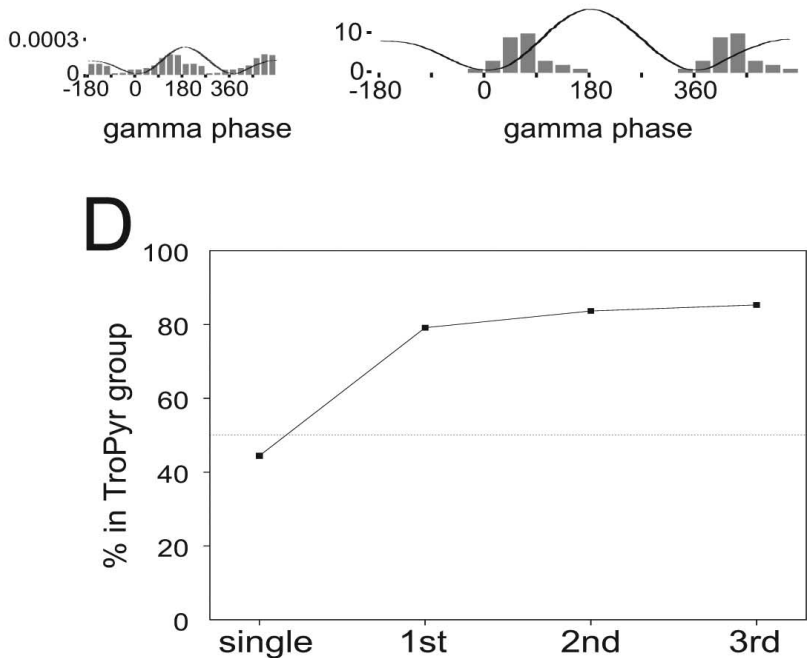

Figure 5. Gamma oscillatory firing of pyramidal cells during single spike and complex spike bursts firing modes. $A, B$, Left, Gamma firing-phase histograms of a representative RisPyr and TroPyr cell during single-spike and burst firing. Right, Cell-count histograms of preferred gamma phases for cells showing significant phase locking during single-spike and burst firing. Note that most of the RisPyr cells ceased to phase lock to gamma during complex spike bursts, whereas the preferred gamma phase of TroPyr cell shifted for successive spikes of the burst. $C$, Preferred gamma phase of cells (including both single-spike and burst firings) that exhibited significant gamma modulation for the first spike of the burst. Black bars, Pyramidal cells from the RisPyr group; gray bar, pyramidal cells of the TroPyr group. D. Percentage of cells belonging to the TroPyr group out of all pyramidal cells with significant single spike or burst firing gamma modulation. Successive action potentials with $<10 \mathrm{~ms}$ interspike interval were considered as part of a burst. Traces on the figures show a representative averaged field potential of a gamma oscillatory wave. single, Single spike (TroPyr, $n=155 ;$ RisPyr, $n=194$ ); 1st, first spike of the burst (TroPyr, $n=91$; RisPyr, $n=24)$; 2nd, second spike of the burst (TroPyr, $n=87$; RisPyr, $n=21$ ); 3rd, third spike of the burst (TroPyr, $n=29 ;$ RisPyr, $n=5)$.

at descending theta phases during gamma oscillations, these cells may not exhibit theta-phase precession during gamma oscillations. Instead, they may fire at descending theta phases independent of the animal's location. Alternatively, they may suppress their firing in locations in which phase precessing cells would normally fire outside the descending theta-phase periods. Thus, these cells may show reduced firing when the animal enters its place field compared with when the animal is leaving the field. In contrast, because TroPyr cells did not change their preferred theta phase during gamma oscillations, they are ex-
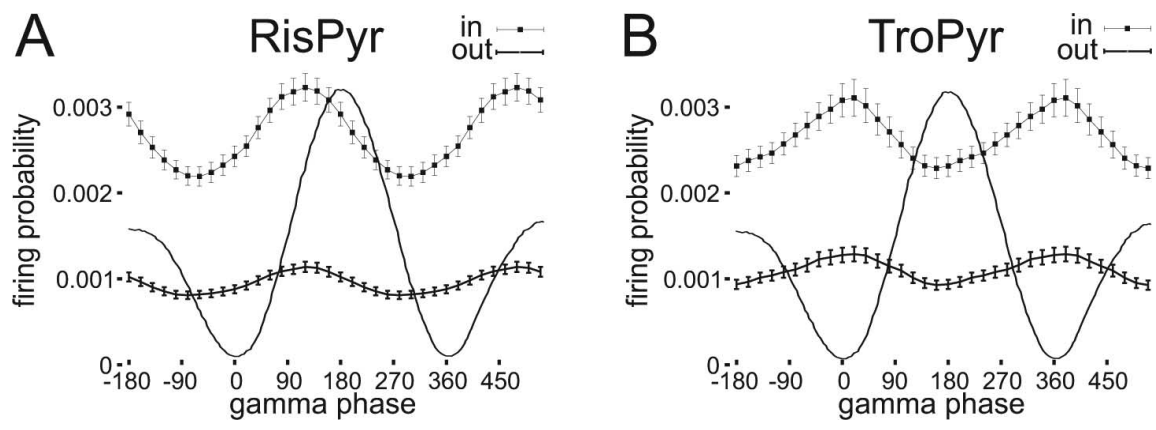

Figure 6. Gamma modulation of place cells during place-related and location-independent firings. Mean ( $\pm \mathrm{SE}$ ) gamma firing-phase histograms for pyramidal cell action potentials measured inside (in) and outside (out) the place field. Note that the absolute gamma modulation of cells (i.e., trough-to-peak firing probability) improved inside the place field. 
A

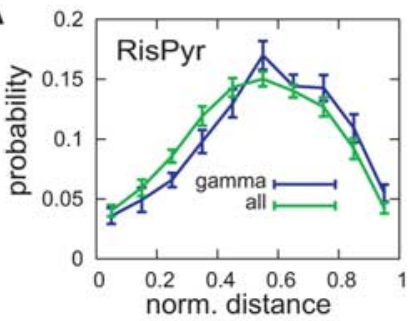

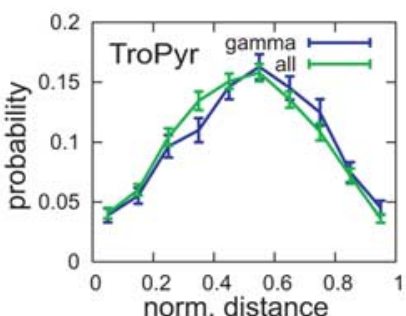

RisPyr

b2

all

b3
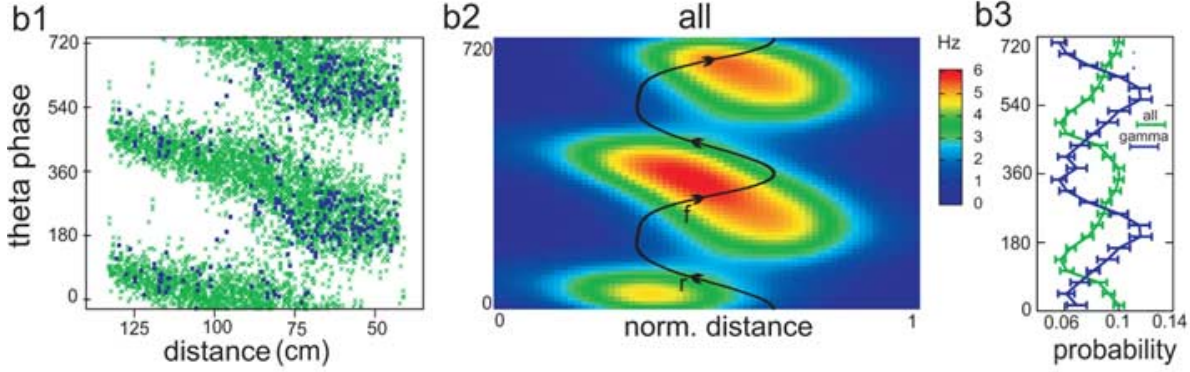

b4

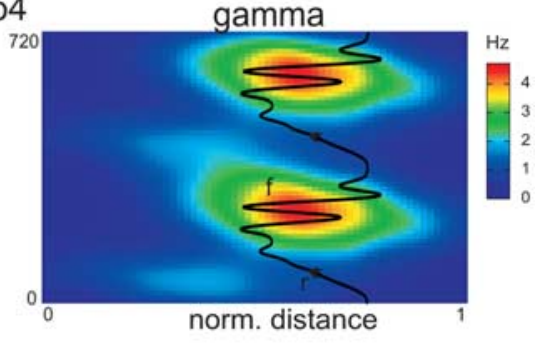

b5

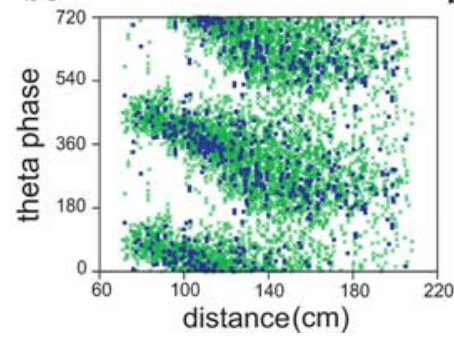

b6

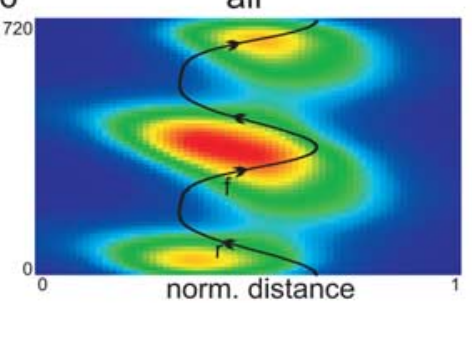

TroPyr

b7

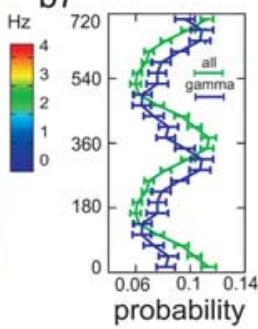

b8

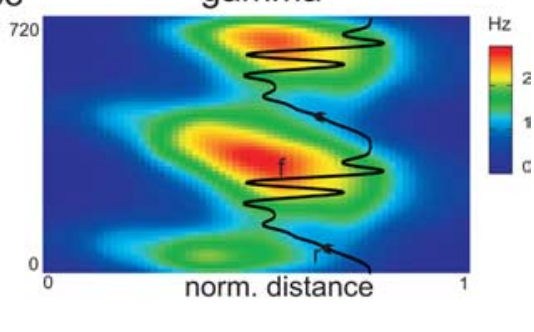

Figure 7. On the linear track, phase precession spans $360^{\circ}$ for TroPyr cells, but is interrupted for RisPyr cells during gamma oscillations. A, Average ( \pm SE) normalized firing probability of action potentials at different place field locations during gamma oscillations and for the whole session. The proportion of spikes were measured at different place field locations and averaged over different cells. Note the asymmetry of firing fields for RisPyr cells, but not for TroPyr cells; that is, RisPyr cells tend to fire more in the second half of the field. $\boldsymbol{B}$, Comparison of phase precession firings for all action potentials and for those during gamma oscillations. $\mathbf{b 1}, \mathbf{b 5}$, Theta-phase precession of a representative TroPyr and RisPyr cell. The theta firing phase of cells was plotted as a function of position within the place field of each cell. Blue dots show action potentials during gamma oscillations, whereas green crosses show the remaining spikes. Note that most of the gamma-associated spikes of the RisPyr cell occurred at the second half of phase precession, but were evenly distributed for the TroPyr cell. $\boldsymbol{b 2}, \boldsymbol{b} \mathbf{b}, \boldsymbol{b} \mathbf{6}, \boldsymbol{b} \mathbf{8}$, The average firing rate for all TroPyr and RisPyr cells as a function of theta phase and normalized distance (theta phase-place map) derived from all action potentials $(\boldsymbol{b} \mathbf{2}, \boldsymbol{b} \boldsymbol{6})$ and those produced during gamma oscillations ( $\boldsymbol{b} 4, \boldsymbol{b} \mathbf{8})$. Normalized distance is the proportion of the place field of each cell traversed from the time of entry. See supplemental Figure 11 A (available at www.jneurosci.org as supplemental material) for the SE of the maps. Note that, during gamma oscillations, the theta-phase precession profile was altered for RisPyr cells, which showed only a weak relationship between theta phase and position, and rarely fired at the rising phase of theta as the animal entered the place field. Traces on the histograms show representative averaged waveforms of a field oscillatory theta and theta-gamma field waveforms. $r$, Rising phase; f, falling phase. $\boldsymbol{b} \mathbf{3}, \boldsymbol{b} \mathbf{7}$, Average ( \pm SE) normalized theta-phase histograms for both cell types using all spikes inside the place field (green) and only those during gamma oscillations (blue).

pected to show normal phase precession during gamma oscillations.

We trained six additional rats to run on the linear or circular tracks and recorded from 1232 pyramidal cells in the CA1-CA3a regions. We included only those cells in our analysis that exhibited significant theta-phase precession and gamma phase-locked firing during the tasks (see Materials and Methods). In total, $9.8 \%$ of the recorded pyramidal cells (TroPyr, 5.3\%; RisPyr, 4.5\%) met our criteria (all $n=121$; TroPyr, $n=66$; RisPyr, $n=$ 55). The firing probability as a function of place field locations showed an asymmetry of firing fields for RisPyr cells but not for TroPyr cells (Fig. 7A), that is, RisPyr cells tended to fire more in the second half of the field. Accordingly, the mean skew of place rate maps was significantly different from zero for RisPyr cells $(-0.177 \pm 0.067, p<0.02, t$ test $)$, but not for TroPyr cells $(-0.049 \pm 0.06, p>0.4)$. To see whether phase precession is altered during gamma oscillations, we calculated the firing rate of these cells as a function of theta phase and relative position inside the place field (phase-place map). The average phase-place map of RisPyr and TroPyr cells was calculated separately for the whole session and during gamma oscillations only (Fig. $7 B b 2, B b 4, B b 6, B b 8)$. The phase precession profile of TroPyr cells was similar during gamma oscillations to that measured for the whole session (Fig. $7 B b 2, B b 4$ ). In contrast, RisPyr cells reduced their firing during gamma oscillations at rising theta phases as the animal entered the place field, showing only a weak relationship between theta phase and position (Fig. 7Bb4). Because of this, they showed a bias toward the late stages of the phase precession (i.e., animal leaving the place field) during gamma oscillations. Accordingly, RisPyr place-rate maps during gamma oscillations showed a negative skew (Fig. 7A) $(-0.338 \pm 0.07, p<0.0001, t$ test); this skew was significantly more negative than that measured for the whole session $(p<0.001$, paired $t$ test). TroPyr cells also showed weaker but significant negative skews in their rate maps during gamma oscillations $(-0.16 \pm 0.069, p<0.02, t$ test $)$ and significant changes in skew compared with the whole session 
A
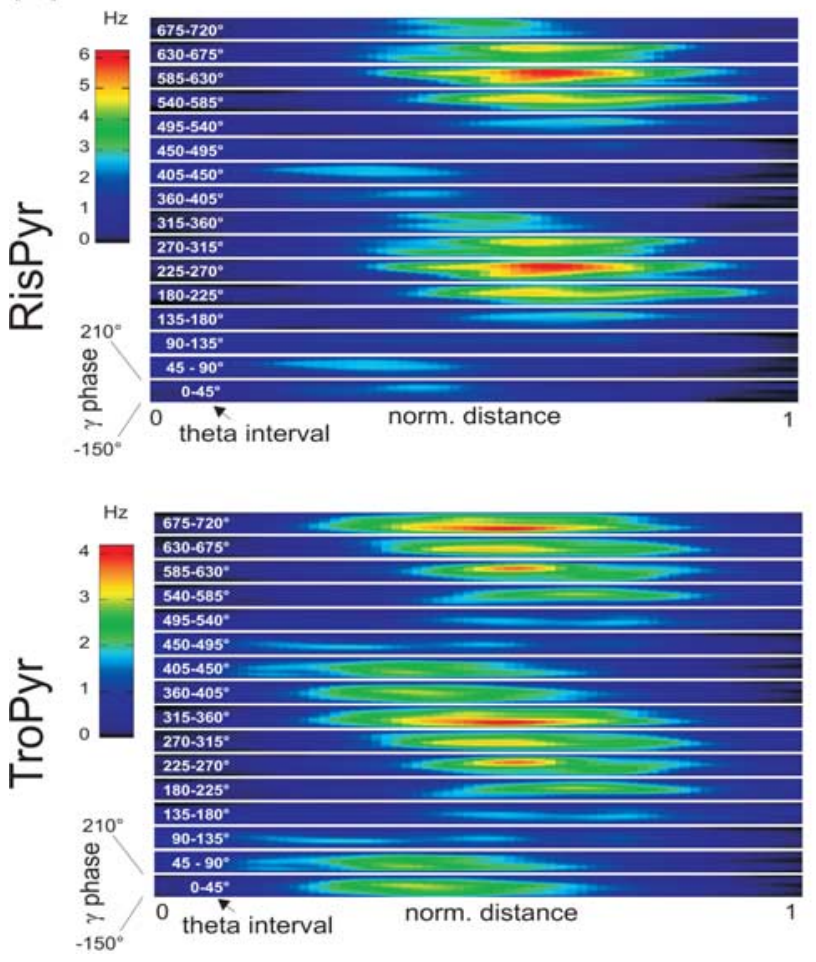

Figure 8. Gamma-modulated firing of TroPyr and RisPyr cells during theta-phase precession. $A$, Color maps show the average firing rate of cells, measured on the linear track, as a function of normalized distance and gamma phase, broken down into $45^{\circ}$ theta-phase intervals. Gamma phase in each theta interval ranges from -150 to $210^{\circ}$. For the $S E$ of the maps, see Figure $11 B$ (available at www.jneurosci.org as supplemental material). $\boldsymbol{B}$, The average gamma firing phase ( $\pm 95 \%$ confidence interval) in each theta interval during theta-phase precession, measured on the linear track. Crosses mark theta intervals in which gamma firing phases were not significant ( $p>0.05$, Rayleigh test). Spikes from different cells that fired in a given theta intervals were averaged for this plot.

( $p<0.04$, paired $t$ test). The theta-phase histograms for RisPyr cells exhibited an approximate half-cycle shift during gamma oscillations, whereas TroPyr cells showed only a minor $(<1 / 4 \mathrm{cy}-$ cle) shift (Fig. 7Bb3,Bb7).

Next, we examined whether the preferred gamma firing phase of place cells changed during the course of theta-phase precession. We analyzed the gamma firing of cells in $45^{\circ}$-wide thetaphase intervals, i.e., action potentials were sorted according to their theta firing phases. Within each theta interval we calculated gamma-phase versus position rate maps and averaged the maps across cells (Fig. $8 A$ ). TroPyr cells showed gamma-locked activity across the extent of phase precession (Fig. $8 A$ ). This plot also shows that the gamma firing phase of these cells varied in different theta-phase intervals. The mean gamma phase of spikes that occurred within a given theta-phase interval changed between intervals ( $p<0.00001$, circular ANOVA) (Fig. $8 B$ ). In contrast, the gamma-locked firing of RisPyr cells was only observed in the later (descending) portions of phase precession, and was not significant near the trough of theta oscillations. Yet even for these cells we observed significant differences in the mean gamma phase of spikes fired in different theta-phase intervals $(p<$ 0.00001; circular ANOVA).

Given that we have seen a tendency on the linear track for the preferred gamma phase of cells to change as a function of theta phase, we examined whether a similar tendency existed in openfield exploration, using a larger database from a previous experiment. As on the linear track, in the open field the preferred gamma phase of cells of both types changed as function of theta-
B
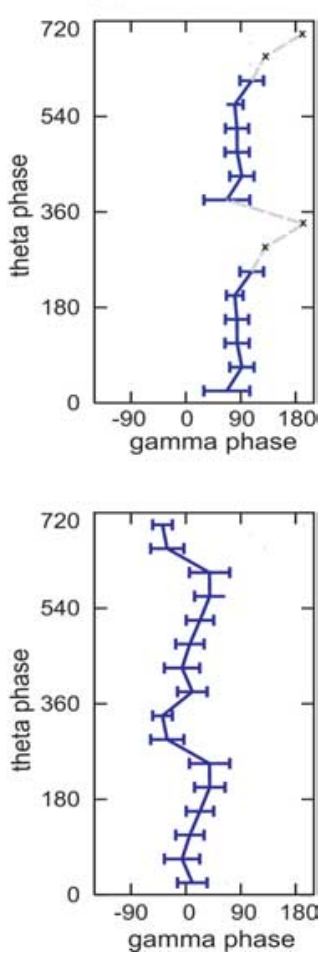

phase interval (Fig. 9A). A circular ANOVA revealed that these changes in preferred gamma phases were significant (Fig. $9 B)$ (all $p$ values $<0.0001$, circular ANOVA).

\section{Discussion}

Here, we have shown that gammamodulated pyramidal cells can be divided into two separate groups on the basis of their preferred gamma phase. These cell groups differed also in their mean preferred theta phases, in the degree of thetaphase change during gamma oscillations and in their tendency to phase lock to gamma oscillations during complex spike burst firing. In addition to the gammarelated firing differences, these cell groups also showed differences in their action potential duration, firing rates and tendency to fire complex spike bursts. This suggests that our gamma-modulated pyramidal cell groups may differ in their intracellular membrane properties or channel distributions. We also demonstrated that the spike timing of pyramidal cells can be simultaneously controlled by both theta and gamma oscillations, enabling the formation of discrete firing sequences within a theta oscillatory period. In this context our finding illustrates that two different groups may support different forms of temporal codes: one supporting transient synchronization patterns that encodes places, and another in which firing sequences distributed across gamma cycles represent movement trajectories.

\section{Rhythmogenesis of in vivo gamma oscillations in the CA3-CA1 regions}

It has been suggested previously that CA3-CA1 gamma oscillations in vivo are generated by similar mechanisms to those of in vitro, carbachol-induced gamma oscillations via recurrent P-I interactions (Csicsvari et al., 2003; Mann et al., 2005; Oren et al., 2006). If P-I interactions generate gamma oscillations, the firing of pyramidal cells should precede interneuron discharge so that pyramidal cells can recruit interneuron activity in the next gamma cycle (Eeckman and Freeman, 1990; Borgers et al., 2005; Oren et al., 2006). If we consider the average population response of cells (Fig. 1A,B), interneuron responses were indeed preceded by pyramidal cells. However, if we consider the individual responses of different cells, not all cells followed this tendency. Of the different interneuron classes, primarily perisomatic-targeting interneurons are expected to participate in the P-I gamma generator because of their strong influence on the spike timing of pyramidal cells. We expect that perisomatic-targeting interneurons are part of the RisInt group as these cells fired before gamma phases associated with current sources in the CA1 pyramidal layer (Csicsvari et al., 2003). Additionally, they fired at descending theta phases when the power of the gamma oscillation is highest, and consequently when perisomatic activity is expected to be strongest (Buhl et al., 2003). This is also the theta phase when parvalbumin positive basket cells fire under anesthesia 
(Klausberger et al., 2003; Somogyi and Klausberger, 2005). With the exception of the waking-theta state, the majority of pyramidal cells fired before RisInt cells. This suggests that P-I cell interactions can account for the rhythmogenesis of gamma oscillations in sleep/immobility states. In waking theta periods only about half of the pyramidal cells (TroPyr) fired before the RisInt cells, whereas the other half (RisPyr) fired at similar phases. Even in this scenario we expect that TroPyr cells together with interneuron populations can act as a P-I gamma rhythm generator. Indeed, computational models have demonstrated that P-I gamma oscillations can be maintained even if the firing of a subgroup of pyramidal cells is driven by an external input and not directly controlled by interneurons (Borgers et al., 2005). However, RisPyr cells fired at similar phases to those of RisInt interneurons. It was shown that interneurons and pyramidal cells should fire at similar gamma phases in the case of I-I interactions (Traub et al., 1996). Thus, it may be possible that RisPyr cells are part of hippocampal subcircuits in which I-I interactions are tuned to generate gamma oscillations in certain instances.

\section{Gamma-modulated inhibitory control} of pyramidal spike timing

The $\mathrm{P}-\mathrm{I}$ gamma generator model assumes that gamma-modulated perisomatic inhibition controls the gamma-locked spike timing of pyramidal cells (Eeckman and Freeman, 1990; Oren et al., 2006). Data related to in vivo hippocampal gamma oscillations also support such inhibitory control (Penttonen et al., 1998; Csicsvari et al., 2003). In this case, both depolarization and membrane conductance levels can potentially alter the spike timing of the pyramidal cell relative to the gamma-locked inhibitory input. This may explain why we have observed changes in the gamma phase of pyramidal cells when they fired at different theta phases (Fig. $8 B-D$ ). This demonstrated that cells were able to change their gamma phases within a limited range, depending on the degree of somatic inhibition and dendritic depolarization they receive at different theta phases. Similar depolarization-induced changes in the spike timing of cells relative to theta oscillations have been demonstrated previously (Kamondi et al., 1998; Magee, 2001). Intrinsic conductances, such as voltage-gated channels, can change the effectiveness of inhibition to time pyramidal cell action potentials (Stuart, 1999). The gamma firing of our cells during complex spike bursts demonstrated that such intrinsic conductances are able to alter the gamma firing phase of cells, or even decouple cells from gamma oscillations. Our TroPyr cells remained phase locked to gamma oscillations during complex spike bursts but the gamma phases of subsequent action potentials within the same bursts were different. In contrast, the majority of the RisPyr cells

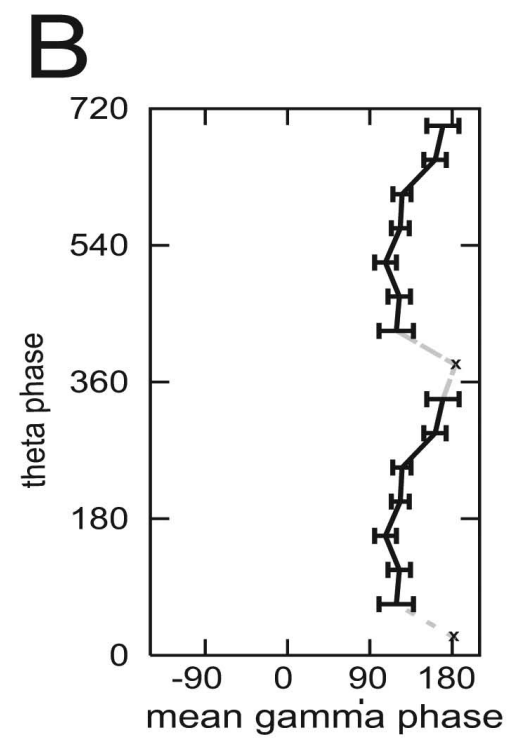

| 20 \# of cells

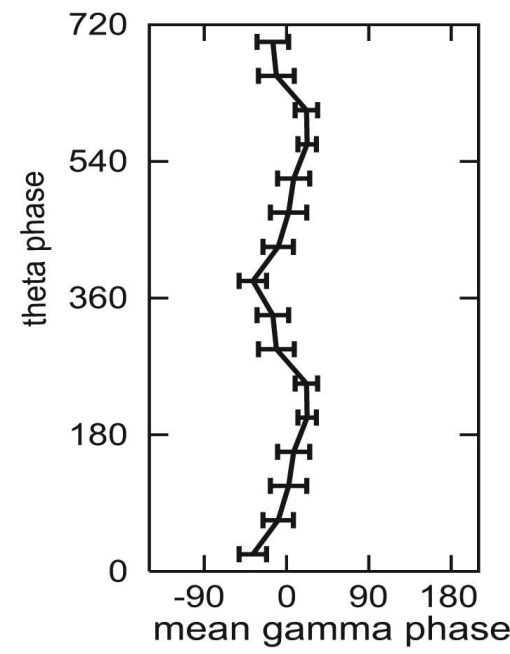

Figure 9. Gamma phase preference changes at different theta intervals. $\boldsymbol{A}$, The preferred gamma phase of cells at different theta intervals during open field exploration. First, the average gamma phase of each cell was calculated at different theta intervals and further averaged across cells of the same group. These spikes were collected during open field exploration in the previous experiment. $\boldsymbol{B}$, Cell-count histograms of preferred gamma firing phases in each theta interval. Note that the theta interval chosen influences the preferred gamma phase of both TroPyr and RisPyr cells (all $p<0.0001$, circular ANOVA).

did not show significant gamma locking during complex spike bursts.

The presence of two discrete pyramidal cell gamma groups questions whether the gamma timings of both groups are controlled by the same perisomatic inhibitory input. Of the two groups, the firing of TroPyr cells can be explained by perisomatic inhibitory control. These cells fired at times when gammamodulated somatic inhibition is expected to be the weakest, at $180^{\circ}$ out of phase from the maximum gamma sources in the CA1 pyramidal cell layer (Csicsvari et al., 2003). Such gammamodulated perisomatic inhibition cannot however explain the firing of RisPyr pyramidal cells. During gamma periods, RisPyr cells fired at gamma and theta phases similar to those of RisInt interneurons. This suggests that RisPyr cells may share a common gamma-modulated input with RisInt interneurons. CA1 interneurons receive gamma-modulated excitation not only from CA1 pyramidal cells but from CA3 pyramidal cells as well, enabling the synchronization of CA1 gamma generators with 
those of CA3 generators (Csicsvari et al., 2003). This gammamodulated drive from CA3 pyramidal cells may pace RisPyr cells during gamma oscillations. Recently it has been shown that CA1 pyramidal dendrites also receive strong gamma-modulated inhibition; bistratified interneurons showed strong gammamodulated firing under anesthesia (Tukker et al., 2007). In addition, cortical input from entorhinal cortex (EC) layer-III cells may contribute to the gamma firing of CA1 interneurons and RisPyr pyramidal cells, as the former fire in gamma-modulated discharges during waking-theta oscillations (Chrobak and Buzsaki, 1998).

The gamma modulation of our cells was not always strong; in many instances cells fired up to $180^{\circ}$ out of phase with their preferred gamma phases. It is possible that the gamma modulation of spike timing of hippocampal cells is even more powerful than shown in this study. Gamma oscillatory waves are relatively small in amplitude, and therefore difficult to detect. Consequently, errors in detecting gamma phases likely produced some reduction in the strength of gamma modulation we were able to detect. However, we also think that individual cells are not perfect oscillators; there is a certain degree of noise present in their phase locking to gamma oscillations. Furthermore, burst firing and theta modulation of gamma phases are factors that introduce variability to the gamma spike timing of cells and thus reducing the strength of their gamma modulation.

\section{RisPyr and TroPyr cells might correspond with anatomical pyramidal classes}

We have shown that our RisPyr and TroPyr pyramidal cells classes differ in several physiological features. Anatomical studies differentiate two classes of CA1 pyramidal cells on the basis of their calbindin (a calcium binding protein) expression (Baimbridge and Miller, 1982). Calbindin immunopositve CA1 pyramidal cells are located closer to stratum radiatum, whereas calbindin immunonegative pyramidal cells are closer to the stratum oriens. Furthermore calbindin immunopositive cells are smaller than the calbindin immunonegative ones. Our RisPyr and TroPyr cell groups might correspond to these anatomical cell classes. Unfortunately, it is not possible to determine layer specific location of our pyramidal cells in extracellular tetrode recordings. One argument against this scenario is that our two cell classes were drawn from $32 \%$ of our pyramidal cells, those that showed significant gamma-modulated firing during waking-theta oscillations. Thus, there was a third group of pyramidal cells that did not show significant gamma modulation during waking theta oscillations. However, we find it unlikely, that these remaining cells would never show gamma-modulated firings because pyramidal cells change their gamma phase-locking tendency in different environments. Indeed we show that more that $50 \%$ of pyramidal cells exhibited significant gamma phase locking in either the familiar or novel environment, but not in both. We therefore do not think that pyramidal cells without gamma modulation represent a third physiological group. Instead it may be, for example that calbindin immunoreactivity correlates with membership in RisPyr/TroPyr group categorization, although we have no evidence to support this.

\section{Different temporal coding properties of the two gamma firing pyramidal groups}

Gamma oscillations may organize temporal firing sequences within theta cycles (Lisman and Idiart, 1995; Lisman, 2005; Koene and Hasselmo, 2007). However, this type of temporalsequence code may not occur during gamma oscillations if the pyramidal cell firing does not span the whole theta cycle. Of the two pyramidal groups, TroPyr cells are able to span the whole theta cycle because their preferred theta firing phases did not change strongly during gamma oscillations and were distributed widely. This enables them to fire in temporal sequences in different gamma cycles and may encode movement paths during thetaphase precession, as previously suggested (Lisman, 2005; Koene and Hasselmo, 2007). On the linear track, we have been able to confirm that the theta-phase precession profile of these cells did not change during gamma oscillations. Furthermore, they maintained gamma-locked firing during the full course of theta-phase precession. This suggests that, indeed, gamma-modulated firing sequences can be formed by TroPyr cells representing a temporal code of movement paths (Lisman, 2005; Koene and Hasselmo, 2007).

In contrast, the preferred theta phases of RisPyr cells were similar during gamma oscillations, so the probability that they fire further apart within a theta cycle is reduced during gamma oscillations, facilitating their synchronized discharges on the descending phases of theta. Furthermore, the gamma-associated phase precession profile revealed that RisPyr cells reduced their firing in the early stages of the phase precession period while maintaining their firing in the later stages. Thus they showed only weak changes in their theta phases as a function of location. These gamma-related changes therefore reduce the chance that these cells will fire in temporal sequences across multiple gamma cycles. Nevertheless, they may facilitate the synchronization of spatially active cells and cell assembly coding of places.

Thus, the presence of two separate pyramidal cell groups with different gamma phase relationships may support different types of cell assembly code: one in which transient synchronization encodes discrete places, and another in which sequential firing patterns distributed across gamma cycles represent movement trajectories. Recent studies suggested that gamma oscillations may have a role in short-term memory processing (Axmacher et al., 2007; Fuchs et al., 2007; Montgomery and Buzsaki, 2007; Sederberg et al., 2007). The behavioral tasks used in these studies required the recall of memory traces after short time periods. Therefore, we propose that gamma-modulated assembly patterns might support the encoding, storage or recall of these memory traces.

\section{References}

Axmacher N, Mormann F, Fernandez G, Cohen MX, Elger CE, Fell J (2007) Sustained neural activity patterns during working memory in the human medial temporal lobe. J Neurosci 27:7807-7816.

Baimbridge KG, Miller JJ (1982) Immunohistochemical localization of calcium-binding protein in the cerebellum, hippocampal formation and olfactory bulb of the rat. Brain Res 245:223-229.

Bauer M, Oostenveld R, Peeters M, Fries P (2006) Tactile spatial attention enhances gamma-band activity in somatosensory cortex and reduces lowfrequency activity in parieto-occipital areas. J Neurosci 26:490-501.

Borgers C, Epstein S, Kopell NJ (2005) Background gamma rhythmicity and attention in cortical local circuits: a computational study. Proc Natl Acad Sci USA 102:7002-7007.

Bragin A, Jando G, Nadasdy Z, Hetke J, Wise K, Buzsaki G (1995) Gamma $(40-100 \mathrm{~Hz})$ oscillation in the hippocampus of the behaving rat. J Neurosci 15:47-60.

Brunel N, Wang XJ (2003) What determines the frequency of fast network oscillations with irregular neural discharges? I. Synaptic dynamics and excitation-inhibition balance. J Neurophysiol 90:415-430.

Buhl DL, Harris KD, Hormuzdi SG, Monyer H, Buzsaki G (2003) Selective impairment of hippocampal gamma oscillations in connexin-36 knockout mouse in vivo. J Neurosci 23:1013-1018.

Buzsaki G, Chrobak JJ (1995) Temporal structure in spatially organized 
neuronal ensembles: a role for interneuronal networks. Curr Opin Neurobiol 5:504-510.

Buzsaki G, Draguhn A (2004) Neuronal oscillations in cortical networks. Science 304:1926-1929.

Buzsaki G, Leung LW, Vanderwolf CH (1983) Cellular bases of hippocampal EEG in the behaving rat. Brain Res 287:139-171.

Chrobak JJ, Buzsaki G (1998) Gamma oscillations in the entorhinal cortex of the freely behaving rat. J Neurosci 18:388-398.

Csicsvari J, Hirase H, Czurko A, Buzsaki G (1998) Reliability and state dependence of pyramidal cell-interneuron synapses in the hippocampus: an ensemble approach in the behaving rat. Neuron 21:179-189.

Csicsvari J, Hirase H, Czurko A, Mamiya A, Buzsaki G (1999) Oscillatory coupling of hippocampal pyramidal cells and interneurons in the behaving Rat. J Neurosci 19:274-287.

Csicsvari J, Jamieson B, Wise KD, Buzsaki G (2003) Mechanisms of gamma oscillations in the hippocampus of the behaving rat. Neuron 37:311-322.

Dragoi G, Buzsaki G (2006) Temporal encoding of place sequences by hippocampal cell assemblies. Neuron 50:145-157.

Eeckman FH, Freeman WJ (1990) Correlations between unit firing and EEG in the rat olfactory system. Brain Res 528:238-244.

Efron B, Tibshirani RJ (1993) An introduction to the bootstrap. New York: Chapman and Hall.

Engel AK, Fries P, Singer W (2001) Dynamic predictions: oscillations and synchrony in top-down processing. Nat Rev Neurosci 2:704-716.

Fell J, Klaver P, Lehnertz K, Grunwald T, Schaller C, Elger CE, Fernandez G (2001) Human memory formation is accompanied by rhinalhippocampal coupling and decoupling. Nat Neurosci 4:1259-1264.

Fisahn A, Pike FG, Buhl EH, Paulsen O (1998) Cholinergic induction of network oscillations at $40 \mathrm{~Hz}$ in the hippocampus in vitro. Nature 394:186-189.

Fisher NI (1993) Statistical analysis of circular data. Cambridge, UK: Cambrige UP.

Fries P, Reynolds JH, Rorie AE, Desimone R (2001) Modulation of oscillatory neuronal synchronization by selective visual attention. Science 291:1560-1563.

Fries P, Nikolic D, Singer W (2007) The gamma cycle. Trends Neurosci 30:309-316.

Fuchs EC, Zivkovic AR, Cunningham MO, Middleton S, LeBeau FE, Bannerman DM, Rozov A, Whittington MA, Traub RD, Rawlins JN, Monyer H (2007) Recruitment of parvalbumin-positive interneurons determines hippocampal function and associated behavior. Neuron 53:591-604.

Hajos N, Palhalmi J, Mann EO, Nemeth B, Paulsen O, Freund TF (2004) Spike timing of distinct types of GABAergic interneuron during hippocampal gamma oscillations in vitro. J Neurosci 24:9127-9137.

Harris KD, Hirase H, Leinekugel X, Henze DA, Buzsaki G (2001) Temporal interaction between single spikes and complex spike bursts in hippocampal pyramidal cells. Neuron 32:141-149.

Henze DA, Borhegyi Z, Csicsvari J, Mamiya A, Harris KD, Buzsáki G (2000) Intracellular features predicted by extracellular recordings in the hippocampus in vivo. J Neurophysiol 84:390-400.

Howard MW, Rizzuto DS, Caplan JB, Madsen JR, Lisman J, AschenbrennerScheibe R, Schulze-Bonhage A, Kahana MJ (2003) Gamma oscillations correlate with working memory load in humans. Cereb Cortex 13:1369-1374.

Jacobs J, Kahana MJ, Ekstrom AD, Fried I (2007) Brain oscillations control timing of single-neuron activity in humans. J Neurosci 27:3839-3844.

Kamondi A, Acsady L, Wang XJ, Buzsaki G (1998) Theta oscillations in somata and dendrites of hippocampal pyramidal cells in vivo: activitydependent phase-precession of action potentials. Hippocampus 8:244-261.

Kanji GK (1999) 100 Statistical Tests. London: SAGE.

Klausberger T, Magill PJ, Marton LF, Roberts JD, Cobden PM, Buzsaki G, Somogyi P (2003) Brain-state- and cell-type-specific firing of hippocampal interneurons in vivo. Nature 421:844-848.

Koene RA, Hasselmo ME (2007) First-in-first-out item replacement in a model of short-term memory based on persistent spiking. Cereb Cortex 17:1766-1781.

Leung LS (1992) Fast (beta) rhythms in the hippocampus: a review. Hippocampus 2:93-98.

Lisman J (2005) The theta/gamma discrete phase code occuring during the hippocampal phase precession may be a more general brain coding scheme. Hippocampus 15:913-922.
Lisman JE, Idiart MA (1995) Storage of $7 \pm 2$ short-term memories in oscillatory subcycles. Science 267:1512-1515.

Magee JC (2001) Dendritic mechanisms of phase precession in hippocampal CA1 pyramidal neurons. J Neurophysiol 86:528-532.

Mann EO, Suckling JM, Hajos N, Greenfield SA, Paulsen O (2005) Perisomatic feedback inhibition underlies cholinergically induced fast network oscillations in the rat hippocampus in vitro. Neuron 45:105-117.

Mitra PP, Pesaran B (1999) Analysis of dynamic brain imaging data. Biophys J 76:691-708.

Montgomery SM, Buzsaki G (2007) Gamma oscillations dynamically couple hippocampal CA3 and CA1 regions during memory task performance. Proc Natl Acad Sci USA 104:14495-14500.

O'Keefe J, Recce ML (1993) Phase relationship between hippocampal place units and the EEG theta rhythm. Hippocampus 3:317-330.

O’Neill J, Senior T, Csicsvari J (2006) Place-selective firing of CA1 pyramidal cells during sharp wave/ripple network patterns in exploratory behavior. Neuron 49:143-155.

Oren I, Mann EO, Paulsen O, Hajos N (2006) Synaptic currents in anatomically identified CA3 neurons during hippocampal gamma oscillations in vitro. J Neurosci 26:9923-9934.

Palhalmi J, Paulsen O, Freund TF, Hajos N (2004) Distinct properties of carbachol- and DHPG-induced network oscillations in hippocampal slices. Neuropharmacology 47:381-389.

Paulsen O, Heggelund P (1996) Quantal properties of spontaneous EPSCs in neurones of the guinea-pig dorsal lateral geniculate nucleus. J Physiol (Lond) 496:759-772.

Penttonen M, Kamondi A, Acsady L, Buzsaki G (1998) Gamma frequency oscillation in the hippocampus of the rat: intracellular analysis in vivo. Eur J Neurosci 10:718-728.

Schmitzer-Torbert N, Jackson J, Henze D, Harris K, Redish AD (2005) Quantitative measures of cluster quality for use in extracellular recordings. Neuroscience 131:1-11.

Sederberg PB, Schulze-Bonhage A, Madsen JR, Bromfield EB, McCarthy DC, Brandt A, Tully MS, Kahana MJ (2007) Hippocampal and neocortical gamma oscillations predict memory formation in humans. Cereb Cortex 17:1190-1196.

Silverman BW (1981) Using kernel density estimates to investigate multimodality. J Royal Statist Soc B 43:97-99.

Singer W (1993) Synchronization of cortical activity and its putative role in information processing and learning. Annu Rev Physiol 55:349-374.

Skaggs WE, McNaughton BL, Wilson MA, Barnes CA (1996) Theta phase precession in hippocampal neuronal populations and the compression of temporal sequences. Hippocampus 6:149-172.

Somogyi P, Klausberger T (2005) Defined types of cortical interneurone structure space and spike timing in the hippocampus. J Physiol (Lond) 562:9-26.

Stuart G (1999) Voltage-activated sodium channels amplify inhibition in neocortical pyramidal neurons. Nat Neurosci 2:144-150.

Thomson DJ (1982) Spectrum estimation and harmonic analysis. Proc IEEE 70:1055-1096.

Towers SK, LeBeau FE, Gloveli T, Traub RD, Whittington MA, Buhl EH (2002) Fast network oscillations in the rat dentate gyrus in vitro. J Neurophysiol 87:1165-1168.

Traub RD, Whittington MA, Stanford IM, Jefferys JG (1996) A mechanism for generation of long-range synchronous fast oscillations in the cortex. Nature 383:621-624.

Traub RD, Bibbig A, Fisahn A, LeBeau FE, Whittington MA, Buhl EH (2000) A model of gamma-frequency network oscillations induced in the rat CA3 region by carbachol in vitro. Eur J Neurosci 12:4093-4106.

Tukker JJ, Fuentealba P, Hartwich K, Somogyi P, Klausberger T (2007) Cell type-specific tuning of hippocampal interneuron firing during gamma oscillations in vivo. J Neurosci 27:8184-8189.

White JA, Banks MI, Pearce RA, Kopell NJ (2000) Networks of interneurons with fast and slow gamma-aminobutyric acid type A (GABAA) kinetics provide substrate for mixed gamma-theta rhythm. Proc Natl Acad Sci USA 97:8128-8133.

Whittington MA, Traub RD, Jefferys JG (1995) Synchronized oscillations in interneuron networks driven by metabotropic glutamate receptor activation. Nature 373:612-615.

Whittington MA, Doheny HC, Traub RD, LeBeau FE, Buhl EH (2001) Differential expression of synaptic and nonsynaptic mechanisms underlying stimulus-induced gamma oscillations in vitro. J Neurosci 21:1727-1738. 